$10-2014$

\title{
Low-Cost Student Experiments in Optics
}

\author{
Robert Polak \\ Loyola University Chicago, rpolak@luc.edu
}

Austin J. Cua

Daniel J. Perez

Mallory Q. Robertson

Justin A. Stuck

See next page for additional authors

Follow this and additional works at: https://ecommons.luc.edu/physics_facpubs

Part of the Physics Commons

\section{Recommended Citation}

Polak, Robert; Cua, Austin J.; Perez, Daniel J.; Robertson, Mallory Q.; Stuck, Justin A.; and Thomas, Jordan M., "Low-Cost Student Experiments in Optics" (2014). Physics: Faculty Publications and Other Works. 45. https://ecommons.luc.edu/physics_facpubs/45

This Article is brought to you for free and open access by the Faculty Publications and Other Works by Department at Loyola eCommons. It has been accepted for inclusion in Physics: Faculty Publications and Other Works by an authorized administrator of Loyola eCommons. For more information, please contact ecommons@luc.edu.

\section{(c) (i) $\Theta$}

This work is licensed under a Creative Commons Attribution-Noncommercial-No Derivative Works 3.0 License. (c) American Association of Physics Teachers, 2014. 


\section{Authors}

Robert Polak, Austin J. Cua, Daniel J. Perez, Mallory Q. Robertson, Justin A. Stuck, and Jordan M. Thomas 


\section{Low-cost student experi- ments in optics}

Robert Polak, Austin J. Cua, Daniel J. Perez, Mallory Q. Robertson, Justin A. Stuck, and Jordan M. Thomas, Department of Physics, Loyola University Chicago, Chicago, IL 60626; rpolak@luc.edu

$\mathrm{T}$ he Next Generation Science Standards place increased importance on the study of waves and electromagnetic radiation. ${ }^{1}$ We provide specifications for two affordable laboratory apparatuses that can be easily built and used as a classroom demonstration or for student experiments in the study of optics. The first is a student diffraction spectrometer, shown in Fig. 1.

The spectrometer is built using many common construc-

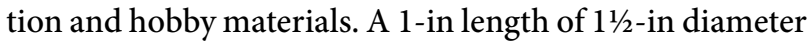
PVC tube is capped at one end with a slit cut with a hacksaw in the cap to allow the light to pass. The tube is supported by two $8.5-\mathrm{x}-11$ in foam board sheets connected by dowels through the top of each foam board. A black drape can be used to block extraneous light. The slit-end of the tube is positioned flush with the second foam board where a 2 -x-2-in diffraction grating (1000 lines/mm purchased from the Online Science Mall) is taped to the outside of the foam board. To view the diffracted light, one half of a 2 -in length of 5 -in diameter clear PVC pipe is placed against the foam board centered on the slit. ${ }^{2}$ The 5 -in diameter best fits the size of a typical protractor, and the clear PVC pipe allows for the spectrum to easily be seen from behind the apparatus (see Fig. 2).

A light source can be placed at the open end of the PVC pipe. The spectrum of the first-order interference pattern is visible on the clear PVC pipe, and the deflection angles can be measured using a protractor. Another effective technique for measuring the angles is to use grid paper taped to the clear PVC pipe. Students marked off the locations of the zeroth and first-order fringes, and then measured the distance between the two to determine the angular location of the first-order fringe (see Fig. 2). By using the angular deviation to calculate wavelength, the two techniques above yielded results within $5 \mathrm{~nm}$ of the dominant wavelength emitted by a colored LED.

A second apparatus is an enhancement of a ray optics set such as Mansion School's Light and Color Prism Set, which contains double concave and double convex lenses as well as convex, concave, and plane mirrors. These sets have been used for ray optics, but we propose a simple light source that allows for these kits to be used to study image formation. This light source has three round LEDs soldered in a row onto a Radio Shack Multipurpose PC board with $1-\mathrm{k} \Omega$ resistors to regulate the current and a 9-V battery as a supply (see Fig. 3). A typical round LED emits light in a narrow cone, and the LED source is built such that the LEDs are near the horizontal

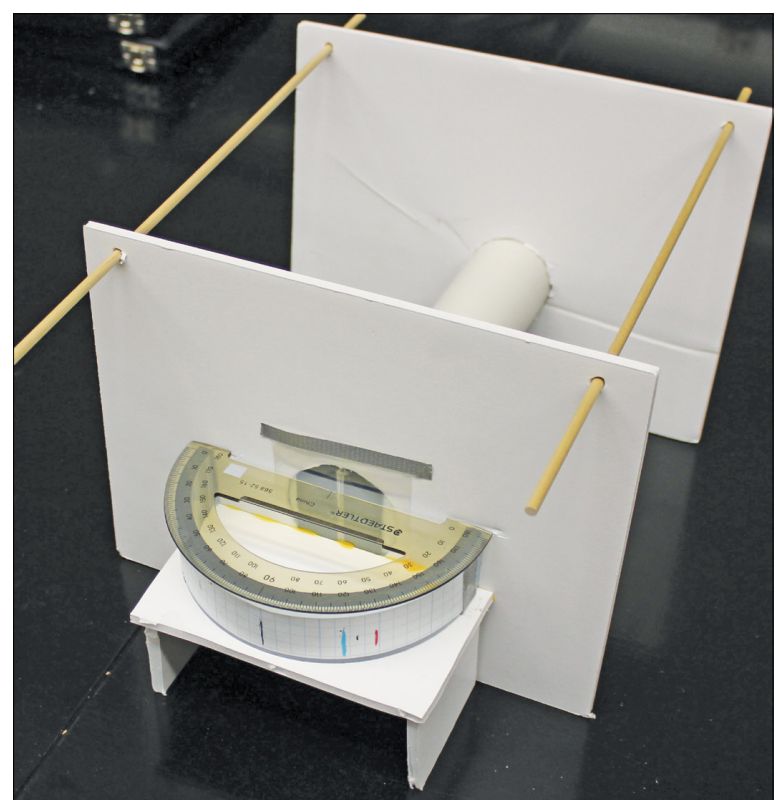

Fig. 1. Student diffraction spectrometer. Students can mark the angular location of different colors of light on the grid paper attached to the clear PVC pipe.

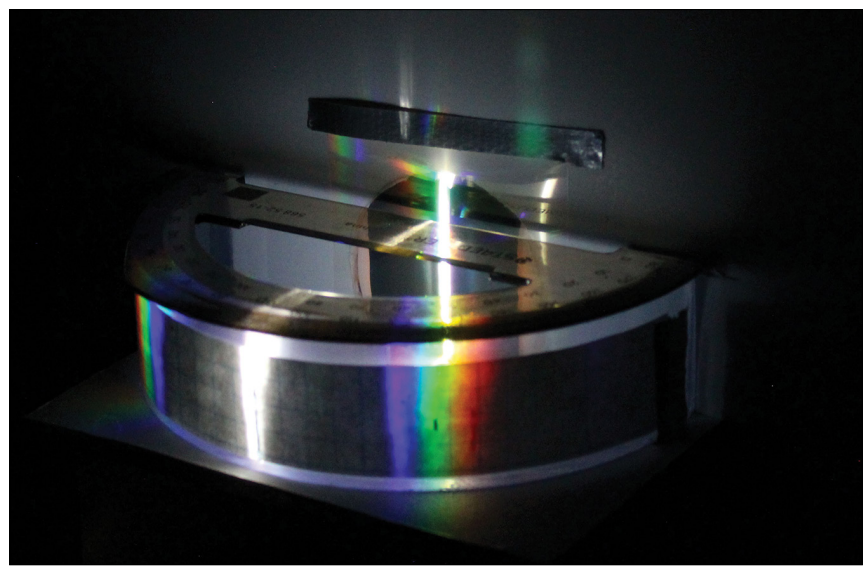

Fig. 2. Diffraction spectrum of a white LED source is visible on the clear PVC pipe.

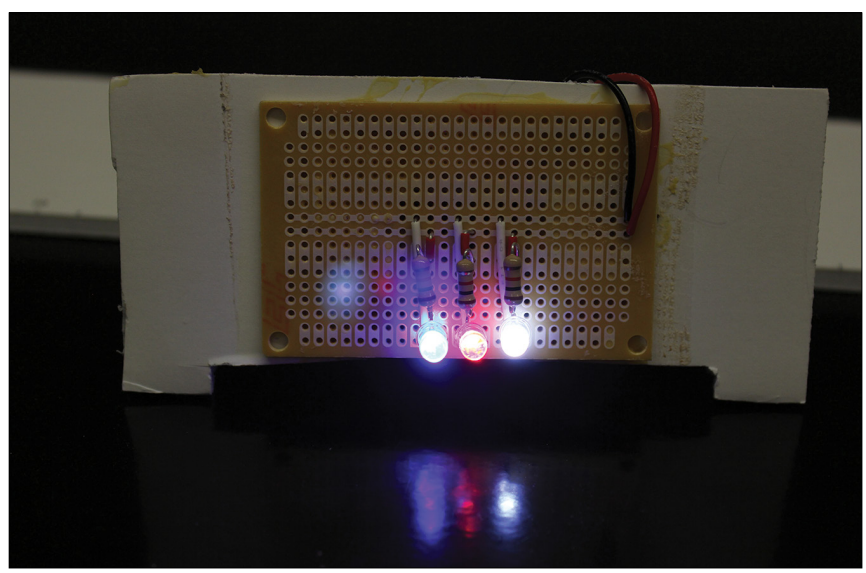

Fig. 3. LED light source that acts as an object for the ray optics set. 
surface where the optical elements from the set are placed. We place the LED source and optical element along a white foam board path that is marked off with tick marks every centimeter to allow for easy measurement of distances between source, optical element, and image.

Figure 4 shows a positive lens placed along the foam board path with the light from the individual LEDs converging after passing through the lens, thereby forming an image. The path of the light can easily be followed as the image is formed on a foam board screen placed at the image plane. This setup can be used to measure magnification, observe image inversion, and confirm both the thin-lens equation and the lensmaker equation. Furthermore, it can be used to demonstrate nearsightedness and farsightedness, as well as exhibit the appropriate corrections to these visual issues using negative and positive lens. It will dispel misconceptions such as what happens to the image when half of the lens is covered. Finally, if a concave mirror is used in conjunction with the LED source, the image location of the mirror is apparent on the foam board without further assistance. By moving the concave mirror relative to the object, the change in image distance can be observed and measured.

These are just a few examples, but there are many more possible experiments that can be done with this particular

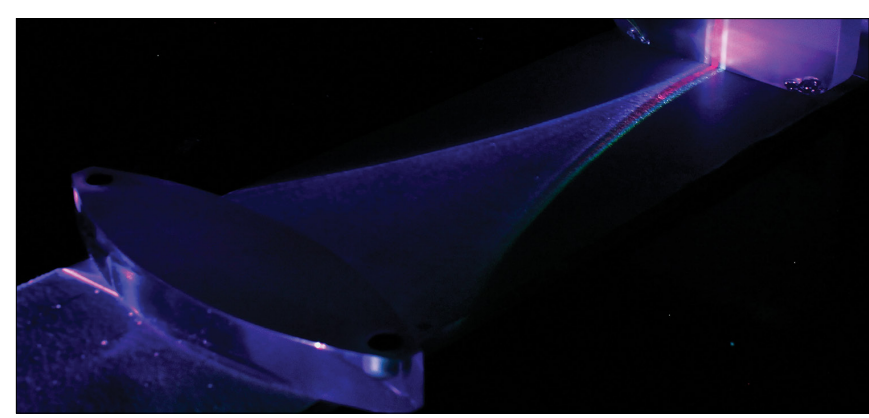

Fig. 4. Light from the object converges and forms an image after passing through the positive lens. The image is visible on the screen.

apparatus. This work was inspired by the talks given at the Education and Training in Optics and Photonics Conference 2013, especially the outreach efforts of Patricia Forbes, Christina Sosa, Vanderlei Bagnato, and their colleagues to extend STEM education into developing countries.

\section{References}

1. NGSS Lead States, Next Generation Science Standards: For States, By States (The National Academies Press, Washington, DC, 2013).

2. One-foot lengths of 5-in diameter clear PVC pipe are available from http://www.flexpvc.com.

\section{And the Survey Says...}

\section{Susan C. White}

American Institute of Physics

Statistical Research Center

College Park, MD 20740; swhite@aip.org

\section{Physics departments with women faculty members}

Last month we examined the representation of women among newly hired physics faculty members. This month we consider the proportion of physics departments with women on their faculties in the professorial ranks-assistant, associate, and full professors. There continue to be some physics departments that have no women faculty members. The percentage is higher at bachelor's-granting departments than at $\mathrm{PhD}$-granting departments, largely because of the small number of faculty members at most bachelor's-granting departments. About $47 \%$ of bachelor's-granting departments had no women faculty members, while one percent of these departments had only women. We studied the number of physics departments with no women among their faculty and found that there are actually fewer of these than would be expected given the small number of faculty members in a typical department and given the overall proportion of women among current physics faculty members. ${ }^{1}$ Next month we will take a closer
Proportion of Physics Departments with Women Faculty* by Highest Degree Granted, 2009-10 Academic Year

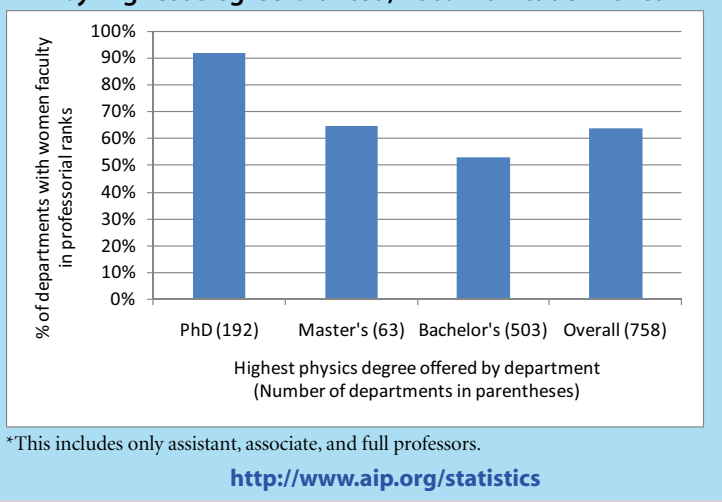

look at the growth in the representation of women among faculty members in $\mathrm{PhD}$-granting departments. If you have any questions or comments, please contact Susan White at the Statistical Research Center of the American Institute of Physics (swhite@aip.org).

1. See Number of Women in Physics Departments: A Simulation Analysis by Susan White \& Rachel Ivie, American Institute of Physics, Statistical Research Center, available at www.aip.org/statistics/women. DOI: 10.1119/1.4895371 